Check for updates

Cite this: RSC Adv., 2017, 7, 20300

\title{
Synthesis of polyoxymethylene dimethyl ethers catalyzed by sulfonic acid-functionalized mesoporous SBA-15
}

\author{
Zhenzhen Xue, (1D a Hongyan Shang, ${ }^{\text {a }}$ Chunhua Xiong, ${ }^{\mathrm{b}}$ Changbo Lu, ${ }^{\mathrm{b}}$ Gaojun An, ${ }^{\mathrm{b}}$ \\ Zailong Zhang, ${ }^{a}$ Chuntao Cui and Mingjie $\mathrm{Xu}^{\mathrm{a}}$
}

Sulfonic acid-functionalized mesoporous SBA-15 ( $\left.\mathrm{SO}_{3} \mathrm{H}-\mathrm{SBA}-15\right)$ with different sulfur loading was synthesized via a post-synthesis method with 3-mercaptopropyltrimethoxysilane (MPTMS) and was used to investigate the catalytic performance for the synthesis of polyoxymethylene dimethyl ethers $\left(P O D E_{n}\right)$ from methylal (DMM) and trioxymethylene (TOX). X-ray diffraction, $\mathrm{N}_{2}$ adsorption-desorption, Fourier transform infrared spectra, ${ }^{13} \mathrm{C}-\mathrm{NMR}$ and ${ }^{29} \mathrm{Si}-\mathrm{NMR}$, elemental analyses, and X-ray fluorescence were used to characterize the structures and sulfur loading of the obtained catalysts, and chemistry titration was carried out to investigate the acid amounts of the catalysts. Through the comparison of the catalysts with different sulfur loading, it was found that the acidity of the catalysts has a decisive effect on the product distribution and the chain length of the products: under the catalysis of the $\mathrm{SO}_{3} \mathrm{H}-\mathrm{SBA}-15(0.8)$ catalyst, which has an acid amount of $0.166 \mathrm{mmol} \mathrm{g}^{-1}$, the highest DMM and TOX conversion and $\mathrm{PODE}_{n}$ yield and selectivity were achieved and the desired chain length of $\mathrm{PODE}_{2-8}$ was obtained. The optimum reaction conditions such as reaction time, temperature, and molar ratio of DMM and TOX were investigated, and by comparison of different reaction temperatures, it was demonstrated that temperature played an important role in the TOX depolymerization rate and selectivity of the main products and by-products. By adjusting the molar ratio of DMM and TOX, it was observed that an increasing amount of TOX was beneficial for promoting the reaction to generate the products with a higher degree of polymerization. The comparison test of the reaction time confirmed that the reaction reached chemical equilibrium within $60 \mathrm{~min}$ and could not be promoted by further extending the time.

Received 5th March 2017

Accepted 14th March 2017

DOI: $10.1039 / c 7 r a 02678 a$

rsc.li/rsc-advances products of high added value and the healthy development of the coal chemical industry.

It is well known that the synthesis of $\operatorname{PODE}_{n}$ is a type of acid catalytic process, at present; there are relatively few reports on the $\mathrm{PODE}_{n}$ synthesis catalysts. Several acid catalysts such as ionexchanged resin, ${ }^{7-9}$ molecular sieve, ${ }^{10,11}$ ionic liquids, ${ }^{12-14}$ heteropoly acids, ${ }^{15} \mathrm{Zr}$-Alumina, ${ }^{16}$ graphene oxide, ${ }^{17}$ solid super acid, ${ }^{18}$ etc. have been studied for the synthesis of $\operatorname{PODE}_{n}$. However, only few catalysts are suitable for industrial application because of the unsatisfactory conversion rate and selectivity of $\mathrm{PODE}_{n}$. Wu et al. ${ }^{11}$ evaluated the catalytic performance of ZSM-5 molecular sieves with different $\mathrm{Si} / \mathrm{Al}$ ratios for the synthesis of $\mathrm{PODE}_{n}$, and they indicated that under the catalysis of ZSM- 5 with the Si/Al ratio of 580, the conversion rate of TOX and selectivity of $\mathrm{PODE}_{n}$ were $85.3 \%$ and $88.5 \%$, respectively. $\mathrm{Li}$ et al. ${ }^{18}$ prepared $\mathrm{SO}_{4}{ }^{2-} / \mathrm{Fe}_{2} \mathrm{O}_{3}-\mathrm{SiO}_{2}$ catalysts with varied acid strength and acid sites, by which the conversion rate of TOX and selectivity of $\mathrm{PODE}_{n}$ were only $81.9 \%$ and $34.4 \%$, respectively. Zhao and coworkers ${ }^{10}$ compared the catalytic performance of HY, HZSM-5, H $\beta$, and HMCM-22, and they indicated that HMCM-22 showed the best catalytic performance; however, the selectivity of $\mathrm{PODE}_{3-8}$ was only $29 \%$. Therefore, an effective
${ }^{a}$ College of Science, China University of Petroleum (East China), Qingdao 266580, Shandong, P. R. China. E-mail: catagroupsh@163.com

${ }^{b}$ Chinese People's Liberation Army Oil Research Institute, Beijing 102300, P. R. China 
catalyst with high activity is urgently required for $\mathrm{PODE}_{n}$ synthesis from methylal and trioxymethylene.

Sulfonic acid mesoporous SBA-15 catalyst as a type of excellent and efficient Brønsted acid catalyst has been applied in different fields such as ethylene polymerization, ${ }^{19,20}$ biodiesel synthesis, ${ }^{21,22}$ bio-oil upgrading, ${ }^{23}$ fatty acid esterification, ${ }^{24-26}$ glycerol acetylation, ${ }^{27}$ and dimethyl ether synthesis. ${ }^{28}$ In our previous research, we synthesized a series of mesoporous $\mathrm{Al}-$ SBA-15 molecular sieves with different $\mathrm{Si} / \mathrm{Al}$ ratios and investigated the influences of acid strength, acid amount, acid type, and pore sizes on the $\mathrm{PODE}_{n}$ synthesis. ${ }^{29}$ In this study, as a continuation of our previous study, a series of sulfonic acidfunctionalized mesoporous SBA-15 with different sulfur loading were synthesized by a post-synthesis method. X-ray diffraction (XRD), $\mathrm{N}_{2}$ adsorption-desorption, X-ray fluorescence (XRF), nuclear magnetic resonance (NMR), Fourier transform infrared (FT-IR) spectroscopy, elemental analysis, and acid-base titration were used to characterize the structure and acidity of the as-synthesized catalysts. Moreover, reusability performance of sulfonic acid-functionalized mesoporous SBA15 was also studied herein.

\section{Experimental}

\subsection{Catalyst preparation}

Preparation of SBA-15. Pure silica SBA-15 materials were synthesized according to the procedure described by Zhao et al. ${ }^{30}$ Typically, $4 \mathrm{~g}$ P123 (Aldrich, $\mathrm{EO}_{20}-\mathrm{PO}_{70}-\mathrm{EO}_{20}$ ) was dispersed in $30 \mathrm{ml}$ of deionized water and $120 \mathrm{ml}$ of $2 \mathrm{M} \mathrm{HCl}$ solution under sufficient stirring, followed by the drop-wise addition of $9 \mathrm{~g}$ TEOS (Aldrich, $\left.\mathrm{Si}\left(\mathrm{OC}_{2} \mathrm{H}_{5}\right)_{4}\right)$ to the abovementioned solution. The mixtures were continuously stirred at room temperature for $24 \mathrm{~h}$ and crystallized in a Teflon-lined autoclave at $100{ }^{\circ} \mathrm{C}$. The mixtures were filtered, washed, dried at $100{ }^{\circ} \mathrm{C}$ for $12 \mathrm{~h}$, and then calcined at $550^{\circ} \mathrm{C}$ for $6 \mathrm{~h}$.

Preparation of sulfonic acid-functionalized SBA-15. The procedure for the synthesis of organosilane-sulfonated SBA-15 was carried out as reported in a previous study. ${ }^{31}$ Typically, $1 \mathrm{~g}$ SBA-15 was dispersed in $30 \mathrm{ml}$ of toluene and stirred for $10 \mathrm{~min}$ under a $\mathrm{N}_{2}$ atmosphere, and specific amounts of 3-mercaptopropyltrimethoxysilane $(0.2,0.5,0.8,1$, and $2 \mathrm{~g}$ per gram SBA15) were added dropwise using an injector. The mixture solution was refluxed at $110{ }^{\circ} \mathrm{C}$ under a $\mathrm{N}_{2}$ atmosphere for $24 \mathrm{~h}$. Then, the mixture was filtered and washed with toluene and ethanol and dried at $60{ }^{\circ} \mathrm{C}$ for $12 \mathrm{~h}$. The obtained solid was oxidized with $30 \mathrm{ml}$ of aqueous $\mathrm{H}_{2} \mathrm{O}_{2}(30 \mathrm{wt} \%$ ) at room temperature for $24 \mathrm{~h}$ under a $\mathrm{N}_{2}$ atmosphere. The catalysts were filtered and washed with deionized water and ethanol and dried at $60{ }^{\circ} \mathrm{C}$ under vacuum for $12 \mathrm{~h}$. The sulfonated SBA- 15 was denoted as $\mathrm{SO}_{3} \mathrm{H}-\mathrm{SBA}-15(n)$, where $n$ refers to the sulfur loading on the SBA-15 surface.

\subsection{Catalyst characterization}

X-ray diffraction (XRD) was carried out using an X'Pert Pro MPD equipment produced by Panalytical with $\mathrm{CuK} \alpha$ radiation. The scan range was set between $0.5^{\circ}$ and $5^{\circ}$ for small angle measurements. $\mathrm{N}_{2}$ adsorption-desorption experiments were carried out via a TriStar II instrument (micromeritics, USA) using nitrogen as the adsorption agent at $-196^{\circ} \mathrm{C}$. The specific surface areas were calculated from the Brunauer-EmmettTeller (BET) equation, and the total pore volumes were calculated by the $\mathrm{BJH}$ method. The $\mathrm{BJH}$ pore sizes were calculated from the desorption branch of the isotherms. The S, C, and $\mathrm{H}$ elemental analyses were carried out by a Thermo EA1112 Element Analyzer. X-ray fluorescence (XRF) was performed via a PANalytical Axios instrument. Fourier transform infrared spectra (FT-IR) were obtained using a Thermo Fisher Nicolet6700 instrument. The ${ }^{13} \mathrm{C}-\mathrm{NMR}$ and ${ }^{29} \mathrm{Si}-\mathrm{NMR}$ spectra were obtained using a Bruker MSL 300 NMR spectrometer with the resonance frequencies of $75.5 \mathrm{MHz}$ and $59.6 \mathrm{MHz}$, respectively. Thermogravimetric analysis was carried out under a high-purity $\mathrm{N}_{2}$ atmosphere at the heating rate of $10{ }^{\circ} \mathrm{C} \mathrm{min}^{-1}$. The acid amounts of the catalysts were detected via a titration method as follows: $0.1 \mathrm{~g}$ of $\mathrm{SO}_{3} \mathrm{H}-\mathrm{SBA}-15$ catalyst was added to $20 \mathrm{ml}$ of $\mathrm{NaCl}(2 \mathrm{M})$ aqueous solution; the mixture was stirred at room temperature for $12 \mathrm{~h}$ and then titrated with $0.05 \mathrm{M} \mathrm{NaOH}$ solution. ${ }^{32,33}$

\subsection{Catalytic performance test}

Experiments for the catalytic performance tests were carried out using a $100 \mathrm{ml}$ stirred autoclave reactor. DMM, TOX, and $\mathrm{SO}_{3} \mathrm{H}-$ SBA-15 catalysts were quantitatively loaded into the reactor. The amounts of DMM and TOX were basically added according to the molar ratio from $2.5: 1$ to $1: 2$ and the amount of $\mathrm{SO}_{3} \mathrm{H}-$ SBA-15 catalysts were $2 \mathrm{wt} \%$ of the total amount of the feedstock loading. The reaction temperature was set at $70-130{ }^{\circ} \mathrm{C}$ and controlled with $\pm 1{ }^{\circ} \mathrm{C}$ of the set value via a modular controller; the reaction times were set from 20 to $120 \mathrm{~min}$. The reaction pressure was fixed at $1 \mathrm{MPa}$ and the agitation speed was set at $300 \mathrm{rpm}$.

Synthetic products were analyzed by an Agilent 7820 gas chromatograph with an FID detector. An Agilent HP-5 capillary column $(30 \mathrm{~m} \times 0.32 \mathrm{~mm} \times 0.25 \mu \mathrm{m})$ was used. Chromatographic conditions were set as follows: injection port temperature, $280{ }^{\circ} \mathrm{C}$; detector temperature, $280{ }^{\circ} \mathrm{C}$; oven temperature program: initially the temperature was maintained at $32^{\circ} \mathrm{C}$ for $5 \mathrm{~min}$, then increased to $45{ }^{\circ} \mathrm{C}$ at the rate of $3{ }^{\circ} \mathrm{C} \mathrm{min}{ }^{-1}$, and finally to $245{ }^{\circ} \mathrm{C}$ at the rate of $50{ }^{\circ} \mathrm{C} \min ^{-1}$ and maintained for $5 \mathrm{~min}$. The internal standard method was adopted as a quantitative method and octane was used as the internal standard.

To estimate the conversion of feedstocks and the yield and selectivity of $\mathrm{PODE}_{n}$, the calculation formulas were employed as follows: DMM conversion:

$$
X_{\mathrm{DMM}}=\frac{m_{\mathrm{DMM}, \text { feed }}-m_{\mathrm{DMM}, \text { product }}}{m_{\mathrm{CH}_{2} \mathrm{O}, \text { feed }}} \times 100 \%
$$

TOX conversion:

$$
X_{\mathrm{CH}_{2} \mathrm{O}}=\frac{m_{\mathrm{CH}_{2} \mathrm{O}, \text { feed }}-m_{\mathrm{CH}_{2} \mathrm{O}, \text { product }}}{m_{\mathrm{CH}_{2} \mathrm{O}, \text { feed }}} \times 100 \%
$$


$\operatorname{PODE}_{n}$ yield:

$$
Y_{\mathrm{PODE}_{n}}=\frac{m_{\mathrm{PODE}_{n}, \text { product }}}{m_{\mathrm{CH}_{2} \mathrm{O}+\mathrm{DMM}, \text { feed }}} \times 100 \%
$$

$\operatorname{PODE}_{n}$ selectivity:

$$
S_{\mathrm{PODE}_{n}}=\frac{m_{\mathrm{PODE}_{n}}}{\sum_{n>1} m_{\mathrm{PODE}_{n}}} \times 100 \%
$$

where $m_{\mathrm{DMM} \text {,feed }}$ and $m_{\mathrm{CH}_{2} \mathrm{O} \text {,feed }}$ is the feeding quality of methylal and trioxymethylene, respectively; $m_{\mathrm{DMM} \text {,product }}$ and $m_{\mathrm{CH}_{2}-}$ o,product is the quality of methylal and trioxymethylene in the product, respectively.

\section{Results and discussion}

\subsection{Structural features of the catalysts}

The small angle XRD patterns of SBA-15 and $\mathrm{SO}_{3} \mathrm{H}-\mathrm{SBA}-15$ with different sulfur loading are shown in Fig. 1. All the samples have three well-resolved diffraction peaks at about $0.92^{\circ}, 1.55^{\circ}$, and $1.77^{\circ}$, corresponding to the (100), (110), and (200) reflections, respectively, which can be identified as typical two-dimensional hexagonal mesostructures (space group $\mathrm{p} 6 \mathrm{~mm}$ ). XRD patterns for $\mathrm{SO}_{3} \mathrm{H}-\mathrm{SBA}-15$ catalysts did not change after the grafting process, evidencing that the two-dimensional hexagonal mesostructure was stable during the functionalization process. ${ }^{23}$

The $\mathrm{N}_{2}$ adsorption-desorption isotherms and pore size distribution of SBA-15 and $\mathrm{SO}_{3} \mathrm{H}-\mathrm{SBA}-15$ are shown in Fig. 2. It can be seen that both the SBA-15 and $\mathrm{SO}_{3} \mathrm{H}-\mathrm{SBA}-15$ catalysts show type IV isotherm with $\mathrm{H} 1$ hysteresis capillary at $0.65<P / P_{0}$ $<0.80$ due to the presence of mesoporous structure and have narrow pore size distribution, which centralizes at about $6.5 \mathrm{~nm}$.

The physical properties of $\mathrm{SO}_{3} \mathrm{H}-\mathrm{SBA}-15$ catalysts are shown in Table 1. The specific surface and pore volume and pore diameter of SBA-15 are $747 \mathrm{~m}^{2} \mathrm{~g}^{-1}, 1.04 \mathrm{~cm}^{3} \mathrm{~g}^{-1}$, and $5.92 \mathrm{~nm}$, respectively, and the surface area, pore volume, and pore sizes of the as-synthesized materials gradually decreased with the increase of sulfur loading, indicating that the grafting reactions not only proceeded on the surface of the catalyst, but also

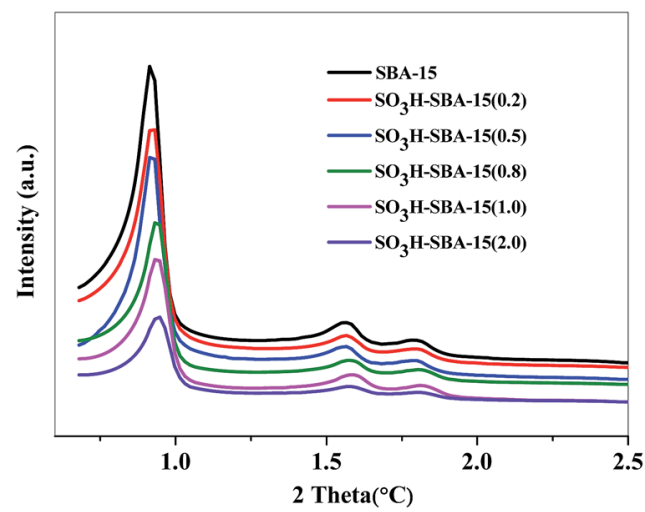

Fig. 1 Small angle XRD patterns of SBA-15 and $\mathrm{SO}_{3} \mathrm{H}-\mathrm{SBA}-15$ with different sulfur loading.
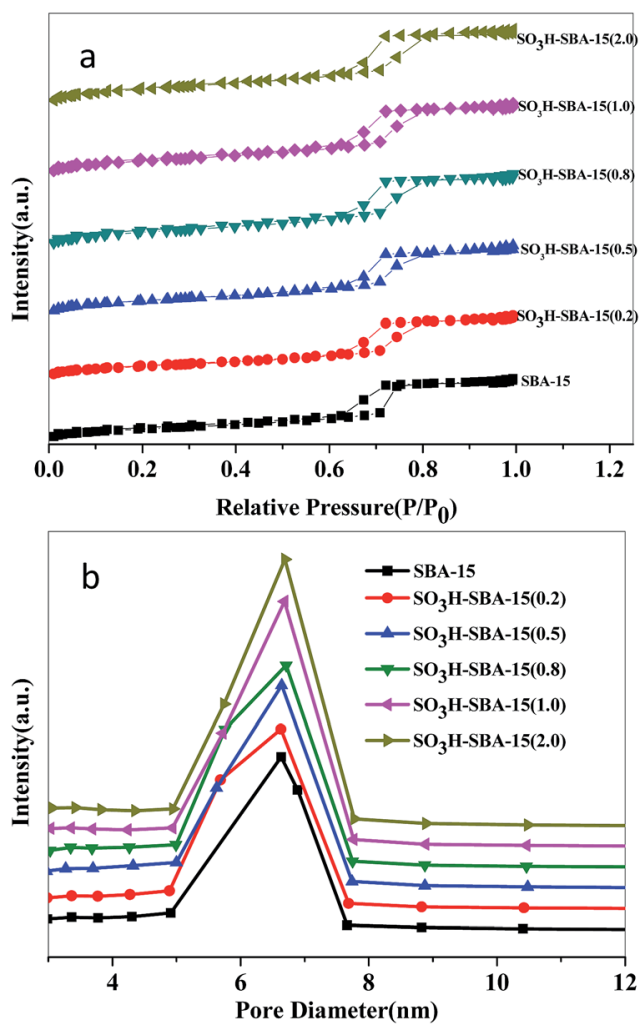

Fig. $2 \mathrm{~N}_{2}$ adsorption-desorption isotherms (a) and pore size distribution (b) of SBA-15 and $\mathrm{SO}_{3} \mathrm{H}-\mathrm{SBA}-15$.

occurred inside of the pore and caused a certain degree of plugging phenomenon. The sulfur loadings of $\mathrm{SO}_{3} \mathrm{H}-\mathrm{SBA}-15$ catalysts, which are shown in Table 1, were determined by elemental analysis and further confirmed via XRF detection. It can be seen that the sulfur contents on the surface of SBA-15 supports gradually increased with the increase of silane concentration, and the actual measured sulfur contents are always lower than that of the feeding amount used for the grafting, which is consistent with a previous report. ${ }^{31}$ Acid amounts of $\mathrm{SO}_{3} \mathrm{H}-\mathrm{SBA}-15$ catalysts with different sulfur loading are shown in Table 1 . The acid amounts are proportional to the sulfur content of the catalyst and gradually increased from 0.056 to $0.443 \mathrm{mmol} \mathrm{g}^{-1}$.

Infrared spectrum detection was used as a qualitative method to identify whether silane was successfully grafted on the silica surface. ${ }^{31,34}$ The strong and wide absorption band at $1093 \mathrm{~cm}^{-1}$ can be attributed to the $\mathrm{Si}-\mathrm{O}-\mathrm{Si}$ antisymmetric stretching vibration (Fig. 3). The bands at $809 \mathrm{~cm}^{-1}$ and 460 $\mathrm{cm}^{-1}$ are assigned to the $\mathrm{Si}-\mathrm{O}$ stretching vibration and bending vibration, respectively. The peak at $958 \mathrm{~cm}^{-1}$ belongs to the bending vibration absorption peaks of the $\mathrm{Si}-\mathrm{OH}$ bond. The attachment of silane on the silica surface was identified by the bands at $2940 \mathrm{~cm}^{-1}$ and $2854 \mathrm{~cm}^{-1}$, which are assigned to the asymmetric and symmetric stretching peaks of methylene, and the band at $1460 \mathrm{~cm}^{-1}$ can be attributed to the methylene symmetric bending vibration.

The incorporation of silane on the silica surface was further confirmed by ${ }^{29}$ Si MAS NMR and ${ }^{13}$ C-MAS NMR. ${ }^{31,35-37}$ The ${ }^{13} \mathrm{C}$ 
Table 1 Physical properties of $\mathrm{SO}_{3} \mathrm{H}-\mathrm{SBA}-15$ catalysts

\begin{tabular}{|c|c|c|c|c|c|c|}
\hline Catalyst & $\begin{array}{l}\text { Specific surface } \\
\text { area } \mathrm{m}^{2} \mathrm{~g}^{-1}\end{array}$ & $\begin{array}{l}\text { Pore volume } \\
\mathrm{cm}^{3} \mathrm{~g}^{-1}\end{array}$ & $\begin{array}{l}\text { Pore diameter } \\
\mathrm{nm}\end{array}$ & $\begin{array}{l}S \text { content }{ }^{a} \\
\text { wt } \%\end{array}$ & $\begin{array}{l}S \text { content }^{b} \\
\text { wt } \%\end{array}$ & $\begin{array}{l}\text { Amount of acid } \\
\text { sites } \mathrm{mmol} \mathrm{g}^{-1}\end{array}$ \\
\hline SBA-15 & 747 & 1.04 & 5.92 & - & - & - \\
\hline $\mathrm{SO}_{3} \mathrm{H}-\mathrm{SBA}-15(0.5)$ & 639 & 0.98 & 5.86 & 0.42 & 0.43 & 0.132 \\
\hline $\mathrm{SO}_{3} \mathrm{H}-\mathrm{SBA}-15(0.8)$ & 625 & 0.95 & 5.85 & 0.53 & 0.54 & 0.166 \\
\hline $\mathrm{SO}_{3} \mathrm{H}-\mathrm{SBA}-15(1.0)$ & 618 & 0.92 & 5.81 & 0.84 & 0.89 & 0.262 \\
\hline
\end{tabular}

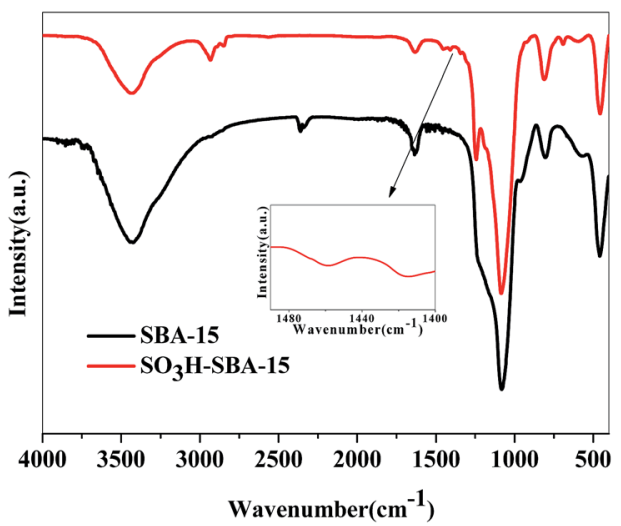

Fig. 3 The Fourier transform infrared spectra of SBA-15 and $\mathrm{SO}_{3} \mathrm{H}-$ SBA-15 catalysts.

MAS NMR spectra of $\mathrm{SO}_{3} \mathrm{H}-\mathrm{SBA}-15(0.8)$ (Fig. 4(A)) exhibit the signals at $12.77,17.52$, and $55.39 \mathrm{ppm}$, which are assigned to the $\mathrm{C} 1, \mathrm{C} 2$, and $\mathrm{C} 3$ carbon peaks, respectively. No peak can be found at about 23 and 41 ppm, indicating that no disulphide was formed during the preparation. Fig. 4(B) shows the ${ }^{29} \mathrm{Si}$ MAS NMR spectra of $\mathrm{SO}_{3} \mathrm{H}-\mathrm{SBA}-15(0.8)$. The two distinct resonances at $-112 \mathrm{ppm}$ and $-103 \mathrm{ppm}$ refer to $\mathrm{Q} 4\left[\mathrm{Si}(\mathrm{OSi})_{3}\right]$ and Q3 $\left[\mathrm{HOSi}(\mathrm{OSi})_{3}\right]$, respectively. The spectrum of $\mathrm{SO}_{3} \mathrm{H}-\mathrm{SBA}-15(0.8)$ shows another two resonances at $-67 \mathrm{ppm}$ and $-59 \mathrm{ppm}$, which illustrate that the $\mathrm{Si}-\mathrm{C}$ bonds were successfully generated, and the organic functional groups were incorporated into the frameworks.

\subsection{Catalytic performance}

The catalytic performance of $\mathrm{SO}_{3} \mathrm{H}-\mathrm{SBA}-15$ catalysts with different sulfur loading for the synthesis of $\mathrm{PODE}_{n}$ is presented in Fig. 5. There is a significant influence of the sulfur loading on the conversion rate of feedstock DMM and TOX and the selectivity and yield of main product $\mathrm{PODE}_{2-8}$. It can be seen from Fig. 5a that the conversion of DMM and TOX and the yield of PODE $_{2-8}$ first increased and then decreased when the sulfur loading increased from 0.2 to $2 \mathrm{wt} \%$ and reached maximum values of $51.84,95.57$, and $61.86 \%$, respectively, under the catalysis of $\mathrm{SO}_{3} \mathrm{H}-\mathrm{SBA}-15(0.8)$. In addition, as shown in Fig. 5b, with the increase of sulfur loading, the selectivity of by-product methyl formate gradually increased and reached its highest
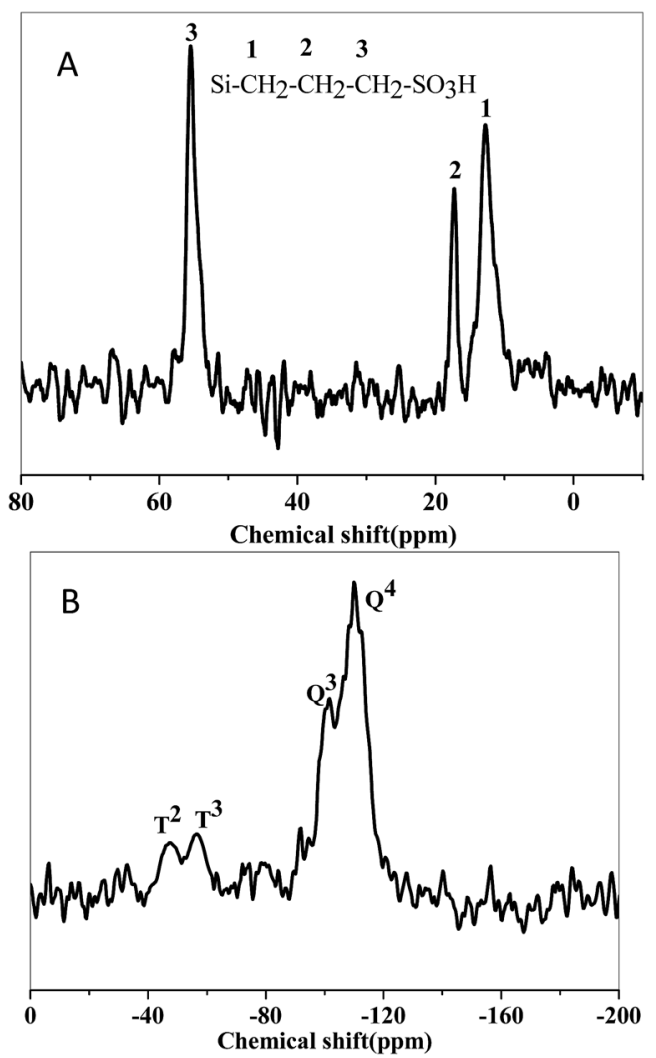

Fig. 4 (A) ${ }^{13} \mathrm{C}-\mathrm{NMR}$ and (B) ${ }^{29} \mathrm{Si}-\mathrm{NMR}$ spectra.

value under the catalysis of $\mathrm{SO}_{3} \mathrm{H}-\mathrm{SBA}-15(2.0)$, which could be attributed to the highest acid amount of $\mathrm{SO}_{3} \mathrm{H}-\mathrm{SBA}-15(2.0)$, as illustrated in Table 1 . Therefore, the $\mathrm{SO}_{3} \mathrm{H}-\mathrm{SBA}-15(0.8)$ catalyst has the best catalytic performance for $\mathrm{PODE}_{n}$ synthesis.

It is well known that the production process of $\mathrm{PODE}_{n}$ can be roughly summarized as two steps: depolymerization of trioxymethylene into formaldehyde monomer and condensation reaction of formaldehyde monomer with DMM and $\mathrm{PODE}_{n-1}$. Moreover, the excessive formaldehyde monomer in the acidic environment will cause the generation of the by-product methyl formate in a Tischenko reaction. ${ }^{38}$ It was reported ${ }^{18}$ that the trioxymethylene dissociation process was a crucial step and depolymerization and transformation situation of trioxymethylene was related with the catalyst acidity, which directly 

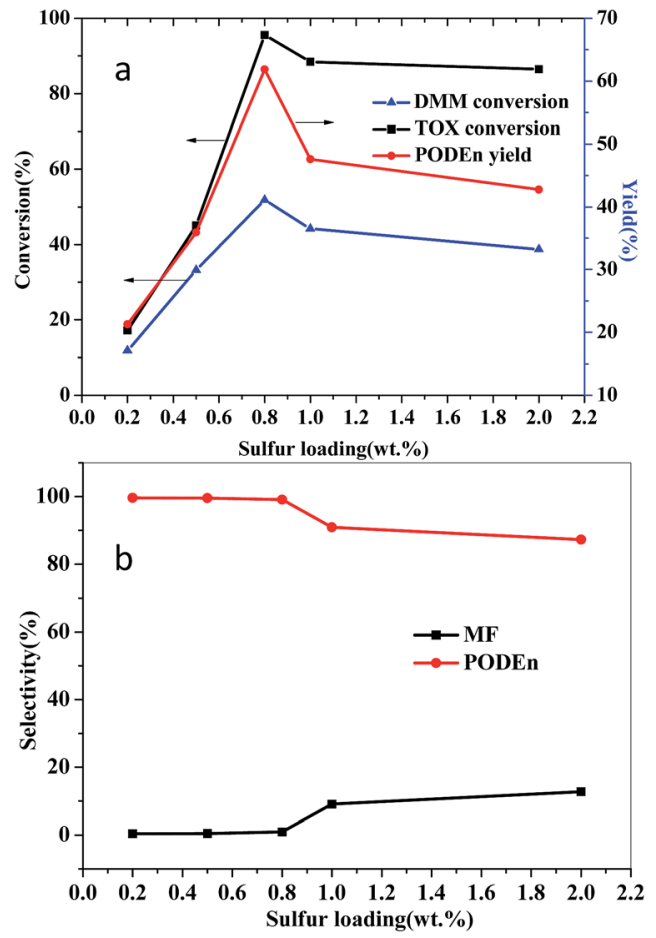

Fig. 5 Catalytic activity of the catalysts with different sulfur loading Reaction conditions: $n(\mathrm{DMM}) / n(\mathrm{TOX})=1$; catalyst loading: $2 \% ; 100{ }^{\circ} \mathrm{C}$; $60 \mathrm{~min} ; 1 \mathrm{MPa}$.

affected the further condensation reaction and side reaction. Fig. 6 shows the reaction and depolymerization tendency of TOX in the presence of catalysts with different acid amounts, which can clearly explain the reaction rules. It can be seen that under the catalysis of $\mathrm{SO}_{3} \mathrm{H}-\mathrm{SBA}-15(0.2)$ and $\mathrm{SO}_{3} \mathrm{H}-\mathrm{SBA}-15(0.5)$ catalysts, which have relatively weak acidity, trioxymethylene was insufficiently depolymerized; therefore, the corresponding the concentration of trioxymethylene, which was converted to the main product $\mathrm{PODE}_{2-8}$ and byproduct $\mathrm{MF}$, was relatively low. Under the catalysis of $\mathrm{SO}_{3} \mathrm{H}-\mathrm{SBA}-15(0.8)$, which has moderate acidity, the undecomposed trioxymethylene in the product reached a minimum value and at the same time the

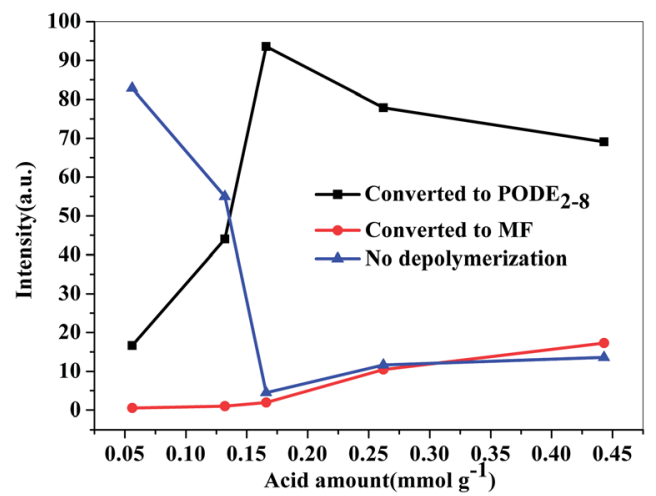

Fig. 6 Conversion and depolymerization tendency of TOX in the presence of catalysts with different acid amounts. depolymerized trioxymethylene, which was converted to $\mathrm{PODE}_{n}$, reached a maximum value. With the further increase of catalyst acidity, the depolymerized trioxymethylene, which was converted to the byproduct methyl formate, obviously increased, indicating that the depolymerization rate of trioxymethylene is far greater than its condensation rate with methylal in the presence of the catalyst with large amounts of acid, and accordingly, the excessive formaldehyde monomer generates methyl formate. Moreover, the trioxymethylene content in the product also increased under the catalysis of $\mathrm{SO}_{3} \mathrm{H}-\mathrm{SBA}-15(1.0)$ and $\mathrm{SO}_{3} \mathrm{H}-\mathrm{SBA}-15(2.0)$, illustrating that the excessive amount of acid will not only promote the occurrence of the side reaction, but also inhibits the depolymerization reaction of trioxymethylene, or accelerates the repolymerization of formaldehyde monomers into trioxymethylene. It can be concluded that the depolymerization of TOX requires a relatively moderate acid amount as an insufficient or excessive amount of acid will lead to incomplete depolymerization.

$\mathrm{PODE}_{n}$ with the structure of $\mathrm{CH}_{3} \mathrm{O}-\left(\mathrm{CH}_{2} \mathrm{O}\right)_{n}-\mathrm{CH}_{3}$ is a mixture of different degrees of polymerization, and with the increase of the degree of polymerization, the cetane number, which is one of the most important indexes for diesel oil, gradually improve. ${ }^{1}$ However, a high degree of polymerization $(n>8)$ will cause the increase of pour point and the cold filter plugging point of the mixture, which is not suitable to be used as a diesel fuel blending component and will need to be returned to the synthetic unit. Moreover, the $\mathrm{PODE}_{2}$ component does not meet the security criterion of the diesel fuel due to its low boiling point and low flash point; therefore, it cannot be used as a diesel blending component either. Thus, among $\mathrm{PODE}_{n}$ products, relatively more $\mathrm{PODE}_{3-8}$ should be generated, and $\mathrm{PODE}_{2}$ and $\mathrm{PODE}_{n>8}$ components should be largely suppressed. The effects of sulfur loading on the product distribution and chain length are shown in Fig. 7. It can be clearly seen that the selectivity of $\mathrm{PODE}_{n}$ with different polymerization and chain length obviously varied with the change of sulfur loading. With the increase of sulfur loading, the selectivity of $\mathrm{PODE}_{2-8}$ increased first and then decreased, and on the $\mathrm{SO}_{3} \mathrm{H}$-SBA15(0.8) catalyst, the selectivity of $\mathrm{PODE}_{3-8}$ reached the highest value among all the catalysts. In addition, the maximum chain length of $\mathrm{PODE}_{n}$ obviously increased with the increase of sulfur

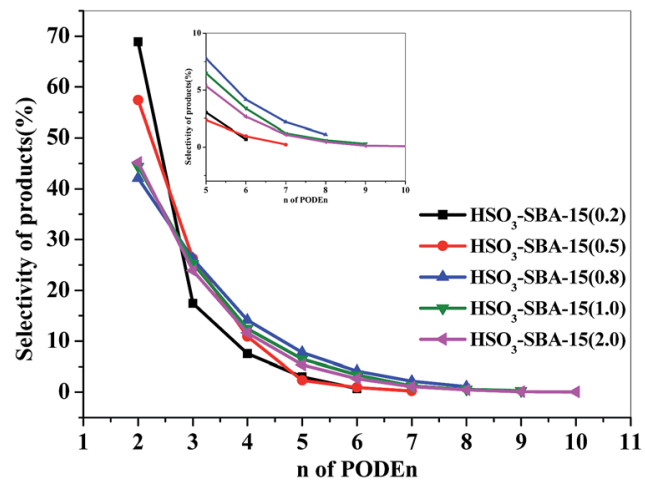

Fig. 7 Effect of sulfur loading on the product distribution and chain length. 


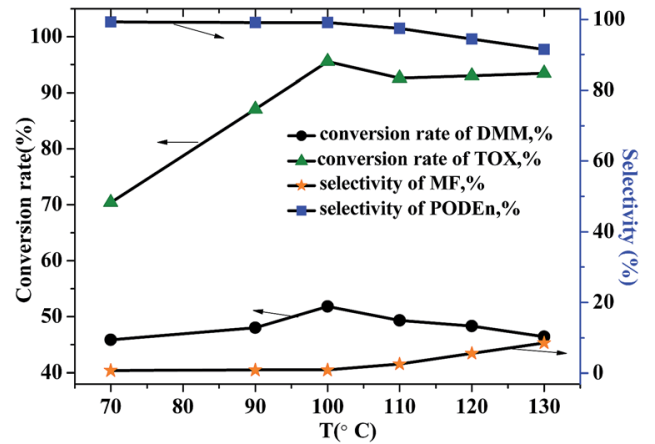

Fig. 8 The influence of temperature on the conversion rate of DMM and TOX and selectivity of $\mathrm{PODE}_{n}$ and by-product on $\mathrm{SO}_{3} \mathrm{H}-\mathrm{SBA}$ 15(0.8) catalyst. Reaction conditions: $n(D M M) / n(T O X)=1$; catalyst loading: 2\%; $60 \mathrm{~min} ; 1 \mathrm{MPa}$.

loading. Under the catalysis of $\mathrm{SO}_{3} \mathrm{H}-\mathrm{SBA}-15(0.2)$ catalyst, only $\mathrm{PODE}_{2-6}$ were generated and the product with the polymerization degree of $n>7$ was not formed. On the $\mathrm{SO}_{3} \mathrm{H}-\mathrm{SBA}-15(0.5)$ catalyst, $\mathrm{PODE}_{7}$ can be detected, and furthermore, $\mathrm{PODE}_{10}$ was generated under the catalysis of $\mathrm{SO}_{3} \mathrm{H}-\mathrm{SBA}-15(2.0)$. Fortunately, only the desired components $\mathrm{PODE}_{3-8}$ were formed under the catalysis of $\mathrm{SO}_{3} \mathrm{H}-\mathrm{SBA}-15(0.8)$. This result fully explains that the acidity of the catalysts also has a decisive effect on the product distribution and the chain length of the products. Thus, it is also an effective way to obtain the desired product distribution by adjusting the acidity of the catalyst.

From a thermodynamic point of view, the ring opening depolymerization reaction of trioxymethylene is endothermic; thus, a relatively higher temperature is in favor of the depolymerization of trioxymethylene. However, the condensation reaction of formaldehyde and methylal is conversely a slightly exothermic reaction. Thus, it is very important to select an appropriate temperature to achieve the maximum efficiency of the reaction. The influence of temperature on the conversion rate of DMM and TOX and selectivity of $\mathrm{PODE}_{n}$ and byproduct is shown in Fig. 8. With the increase of temperature, the conversion rate of TOX gradually increased, indicating that a higher temperature will accelerate the depolymerization process of TOX. A relatively low temperature will lead to the incomplete depolymerization of TOX. However, the selectivity of the byproduct MF also increased with the increase of temperature, especially after a temperature greater than $100{ }^{\circ} \mathrm{C}$. This is probably due to the fact that the depolymerization rate of trioxymethylene is far greater than its condensation rate with methylal at high temperature; thus, the competitive reaction of the formation of the byproduct methyl formate is greatly promoted. Therefore, considering the feedstock conversion rate and product selectivity, $100{ }^{\circ} \mathrm{C}$ is the most appropriate temperature for the $\mathrm{PODE}_{n}$ synthesis.

The molar ratio of feedstocks has a great influence on the conversion rate of the feedstocks and the yield of the products. It can be seen that increasing the amount of trioxymethylene is beneficial for enhancing the yield of $\mathrm{PODE}_{2-8}$ (Fig. 9a) and improving the conversion rate of DMM; however, the conversion rate of TOX was gradually reduced due to the limit of the
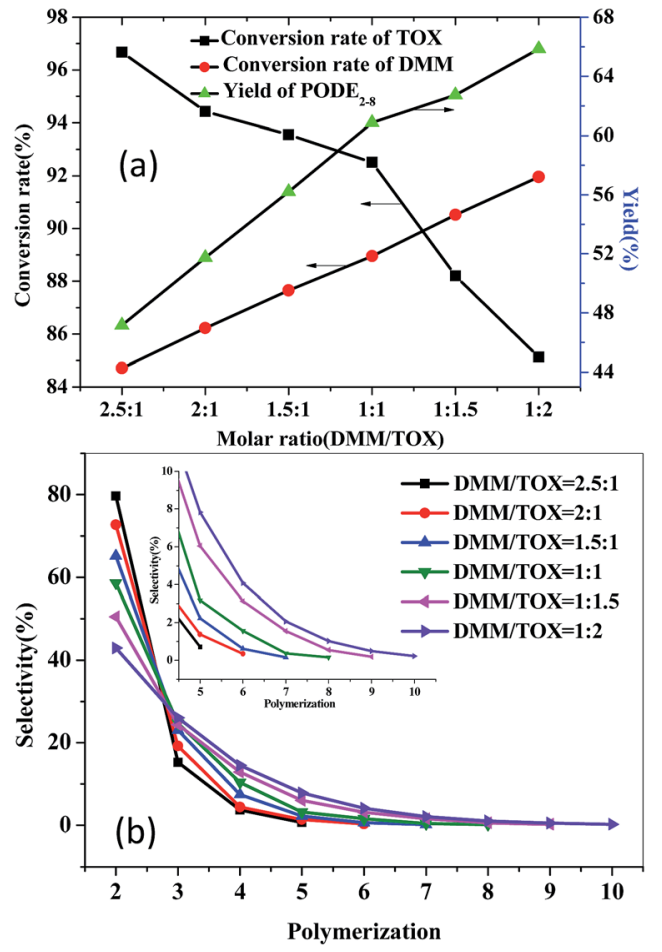

Fig. 9 Effect of the molar ratio of DMM and TOX on the conversion rate of DMM and TOX and yield of $\mathrm{PODE}_{n}$ (a) and product distribution (b). Reaction conditions: $\mathrm{SO}_{3} \mathrm{H}-\mathrm{SBA}-15(0.8)$, catalyst loading: $2 \%$; $100{ }^{\circ} \mathrm{C}$; $60 \mathrm{~min}$; $1 \mathrm{MPa}$.

equilibrium of the reaction. In addition, as shown in Fig. 9b, the product distribution and chain length obviously varied with the change of the molar ratio of DMM and TOX. With the increase of TOX proportion, the selectivity of $\mathrm{PODE}_{2}$ decreased, whereas the selectivity of $\mathrm{PODE}_{3-8}$ gradually increased, indicating that increasing the amount of TOX is in favour of promoting the reaction to generate products with a higher degree of polymerization. When the DMM/TOX molar ratio was $1: 2$, the product with the chain length of 10 was generated. With the increase of DMM proportion, the high degree of polymerization selectivity gradually decreased, and when the molar ratio of DMM/TOX reached $1: 1$, no product of $n>8$ was formed. Therefore, to avoid the generation of products with a high degree of polymerization, a relatively large proportion of methylal was required. Although with the change of the DMM/ TOX molar ratio from $2: 1$ to $1: 2$, the yield of $\mathrm{PODE}_{2-8}$ gradually decreased, whereas the conversion rate of TOX significantly increased. Thus, a relatively large proportion of methylal will not only inhibit the generation of high degree of polymerization products, but also greatly improves the conversion rate of TOX. Therefore, to avoid the generation of a high degree of polymerization products, it is necessary to lose a certain yield of $\mathrm{PODE}_{2-8}$. Considering the yield of $\mathrm{PODE}_{n}$ and conversion of TOX under the premise of no generation of $\mathrm{PODE}_{n}$ in which $n>$ $8,1: 1$ is the optimum molar ratio of DMM and TOX in the reaction system.

The yield of $\mathrm{PODE}_{n}$ and the conversion rate of DMM and TOX all have a significant increase in the reaction for the first 60 


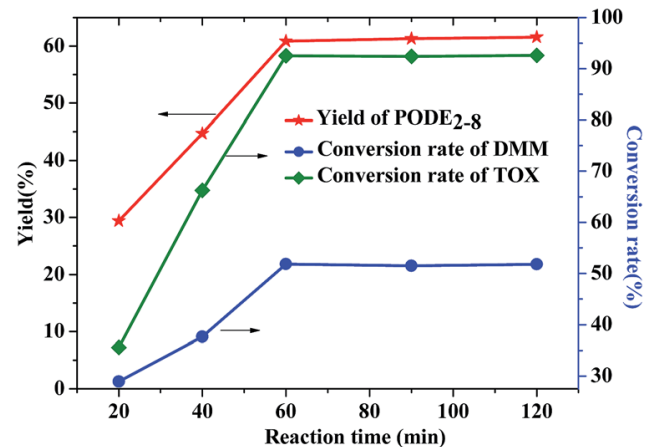

Fig. 10 The influence of reaction time on the conversion rate of DMM and TOX and yield of $\mathrm{PODE}_{n}$ over $\mathrm{SO}_{3} \mathrm{H}-\mathrm{SBA}-15(0.8)$ catalyst. Reaction conditions: $n(\mathrm{DMM}) / n(\mathrm{TOX})=1$; catalyst loading: $2 \% ; 100{ }^{\circ} \mathrm{C} ; 1 \mathrm{MPa}$.

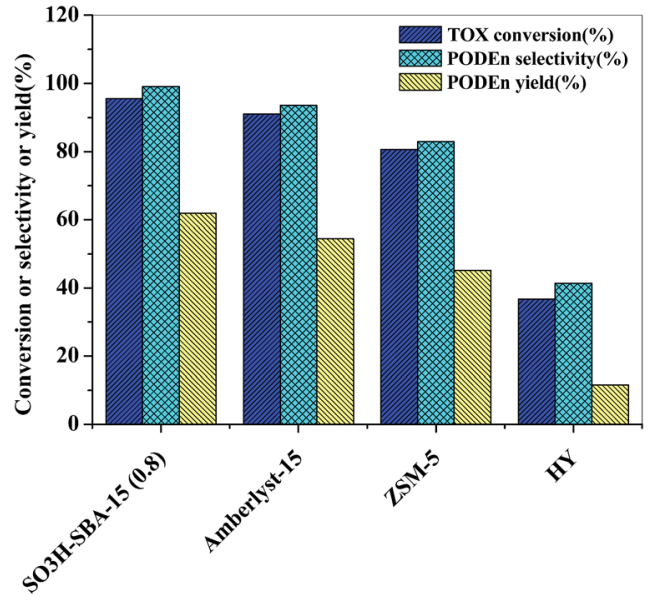

Fig. 11 Comparison of $\mathrm{SO}_{3} \mathrm{H}-\mathrm{SBA}-15(0.8)$, Amberlyst-15, ZSM-5 zeolite, and $\mathrm{HY}$ zeolite for $\mathrm{PODE}_{n}$ synthesis. Reaction conditions: $n(\mathrm{DMM}) / n(\mathrm{TOX})=1$; catalyst loading: $2 \% ; 100{ }^{\circ} \mathrm{C} ; 1 \mathrm{MPa}$.

minutes, which is shown in Fig. 10. Because the depolymerization process of TOX is relatively slow, a certain period of time is required to achieve the balance of trioxymethylene depolymerization. However, when the reaction time is prolonged to $90 \mathrm{~min}$ and $120 \mathrm{~min}$, the conversion rate of feedstocks and the yield of the products are essentially flat compared with those at 60 min, which shows that the reaction system has basically reached chemical equilibrium and cannot be promoted by extending time. Thus, $60 \mathrm{~min}$ is the most appropriate time for $\operatorname{PODE}_{n}$ synthesis.

The catalytic performance of $\mathrm{SO}_{3} \mathrm{H}-\mathrm{SBA}-15(0.8)$ catalyst was further evaluated by comparing with the reference catalysts such as Amberlyst-15 sulfonic acid resin, ZSM-5 zeolite with Si/ $\mathrm{Al}$ ratio of 200 , and $\mathrm{HY}$ zeolite with the $\mathrm{Si} / \mathrm{Al}$ ratio of 5.3 . It can be seen from Fig. 11 that the conversion rate of TOX and the $\mathrm{PODE}_{n}$ yield and selectivity under the catalysis of $\mathrm{SO}_{3} \mathrm{H}-\mathrm{SBA}$ 15(0.8) are obviously higher than those of Amberlyst-15 sulfonic acid resin, and ZSM-5 and $\mathrm{HY}$ zeolite. One reason for the better performance of the $\mathrm{SO}_{3} \mathrm{H}-\mathrm{SBA}-15(0.8)$ catalyst is attributed to the enhanced mesoporosity, which would overcome the diffusion limitation and promote the transformation

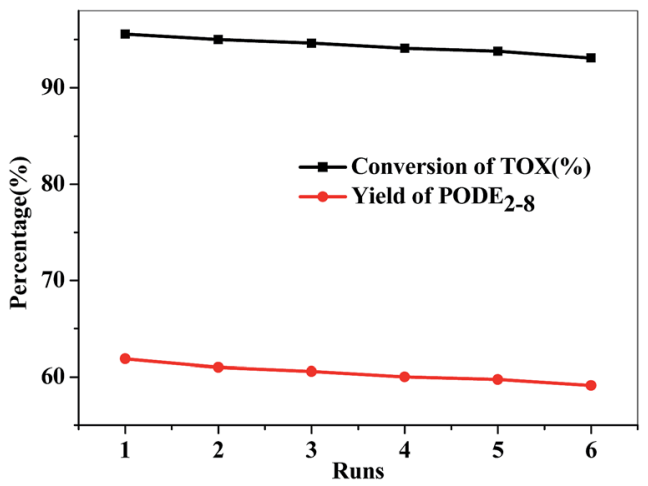

Fig. 12 Recycling experiment of $\mathrm{SO}_{3} \mathrm{H}-\mathrm{SBA}-15(0.8)$ catalyst. Reaction conditions: $n(\mathrm{DMM}) / n(\mathrm{TOX})=1$; catalyst loading: $2 \% ; 100{ }^{\circ} \mathrm{C} ; 1 \mathrm{MPa}$; $60 \mathrm{~min}$

of the reactants and products in the two-dimensional hexagonal mesostructure. Another more important reason is probably ascribed to the moderate acidity of the $\mathrm{SO}_{3} \mathrm{H}$-SBA-15(0.8) catalyst. We know that the depolymerization of TOX requires a relatively moderate acid amount; insufficient or excessive amount of acid will promote the formation of the by-product methyl formate and lead to the incomplete depolymerization of TOX, thus affecting the conversion of TOX and yield of $\operatorname{PODE}_{n}$. There is a relatively high acid amount in the pores of Amberlyst-15 sulfonic acid resin, ZSM-5 zeolite, and HY zeolite, which leads to the far greater depolymerization rate of TOX than its condensation rate with methylal; therefore, a large number of methyl formate is generated and the depolymerization of TOX is suppressed.

The catalytic stability of the as-synthesized catalyst, which is an important index for selecting the catalysts, was evaluated in the $\mathrm{PODE}_{n}$ synthesis. $\mathrm{SO}_{3} \mathrm{H}-\mathrm{SBA}-15(0.8)$ catalyst was used to evaluate the reusability. After completing a catalytic reaction, $\mathrm{SO}_{3} \mathrm{H}-\mathrm{SBA}-15(0.8)$ was separated from the reaction system by filtration and was dried in vacuum at $60{ }^{\circ} \mathrm{C}$ for $12 \mathrm{~h}$ and then used for the next reaction. As illustrated in Fig. 12, the activity of the catalysts only slightly declined after being reused six times; the conversion rate of TOX decreased from $95.57 \%$ to $93.09 \%$,

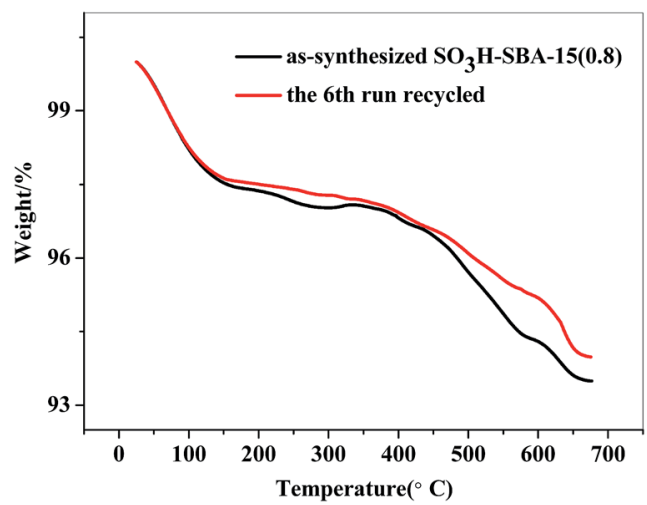

Fig. 13 TGA curves of the as-synthesized and the 6th run recycled $\mathrm{SO}_{3} \mathrm{H}-\mathrm{SBA}-15(0.8)$ catalyst. 
and the yield of $\mathrm{PODE}_{2-8}$ also decreased from $61.86 \%$ to $59.13 \%$. Moreover, the as-synthesized and the 6th run recycled $\mathrm{SO}_{3} \mathrm{H}^{-}$ SBA-15(0.8) catalyst were characterized by elemental analysis and further verified by TGA (Fig. 13), showing that the sulfur content of the catalyst slightly reduced from $0.53 \%$ to $0.51 \%$.

\section{Conclusion}

Herein, $\mathrm{SO}_{3} \mathrm{H}-\mathrm{SBA}-15$ catalysts with different sulfur loading were successfully prepared for the synthesis of $\mathrm{PODE}_{n}$ from DMM and TOX. In the study of the effect of different sulfur loading (acid property) on the catalytic performance, it was found that a moderate amount of acid was required for $\mathrm{PODE}_{n}$ synthesis, as proven by $\mathrm{SO}_{3} \mathrm{H}-\mathrm{SBA}-15(0.8)$ catalyst, which showed the best catalytic performance, in that the conversion rate of DMM and TOX and the yield of $\mathrm{PODE}_{2-8}$ reached high values of $51.84,95.57$, and $61.86 \%$, respectively. Inadequate or excessive amounts of acid will lead to the incomplete depolymerization of trioxymethylene. Moreover, the excessive amount of acid can cause the formation of a large number of by-product, methyl formate. In addition, the acidity of the catalysts also had a decisive effect on the product distribution and the chain length of the products. The optimum reaction conditions were investigated; through the comparison of reaction temperature, it can be concluded that a relatively low temperature ranging from 70 to $90^{\circ} \mathrm{C}$ will lead to the incomplete depolymerization of trioxymethylene, and a higher temperature ranging from 110 to $130{ }^{\circ} \mathrm{C}$ will accelerate the depolymerization process of TOX and greatly promote the formation of the by-product methyl formate; thus, $100^{\circ} \mathrm{C}$ was the most appropriate temperature. By adjusting the molar ratio of DMM and TOX, it was found that an increasing amount of TOX was in favor of improving the yield of $\mathrm{PODE}_{n}$ and promoting the generation of the products with a higher degree of polymerization. Considering a higher product yield and reasonable product chain length, $1: 1$ was the optimum molar ratio of DMM and TOX, at which no $\mathrm{PODE}_{n>8}$ was generated. The reaction time analysis demonstrated that the reaction system had basically reached chemical equilibrium within $60 \mathrm{~min}$ and the reaction could not be promoted by further extending time. Moreover, according to the comparison of $\mathrm{SO}_{3} \mathrm{H}-\mathrm{SBA}-15(0.8)$ catalyst and the reference catalysts, it can be concluded that the $\mathrm{SO}_{3} \mathrm{H}$-SBA-15(0.8) catalyst had better catalytic activity than Amberlyst-15 sulfonic acid resin, and ZSM-5 and HY zeolite for $\mathrm{PODE}_{n}$ synthesis. The activity of $\mathrm{SO}_{3} \mathrm{H}-$ SBA-15(0.8) catalyst just slightly declined after being reused six times, showing good application prospects.

\section{Acknowledgements}

This work was supported by the National Key Technology R\&D Program (No. 2013BAB11B03).

\section{Notes and references}

1 J. Burger, M. Siegert, E. Ströfer and H. Hasse, Fuel, 2010, 89, 3315-3319.
2 Y. S. Lei, Q. Chen and Z. Shen, Acta Chim. Sin., 2009, 67, 767772.

3 H. Liu, Z. Wang, J. Wang, X. He, Y. Zheng, Q. Tang and J. Wang, Energy, 2015, 88, 793-800.

4 J. Liu, H. Wang, Y. Li, Z. Zheng, Z. Xue, H. Shang and M. Yao, Fuel, 2016, 177, 206-216.

5 Y. Li, L. Meng, K. Nithyanandan, T. H. Lee, Y. Lin, C.-f. F. Lee and S. Liao, Fuel, 2016, 184, 864-872.

6 L. Pellegrini, M. Marchionna, R. Patrini, C. Beatrice, N. Del Giacomo and C. Guido, Combustion Behaviour and Emission Performance of Neat and Blended Polyoxymethylene Dimethyl Ethers in a Light-Duty Diesel Engine, SAE Paper 2012-01-1053, 2012.

7 L. Wang, W.-T. Wu, T. Chen, Q. Chen and M.-Y. He, Chem. Eng. Commun., 2014, 201, 709-717.

8 Y. Zheng, Q. Tang, T. Wang, Y. Liao and J. Wang, Chem. Eng. Technol., 2013, 36, 1951-1956.

9 J. Burger, E. Ströfer and H. Hasse, Ind. Eng. Chem. Res., 2012, 51, 12751-12761.

10 Q. Zhao, H. Wang, Z.-F. Qin, Z.-W. Wu, J.-B. Wu, W.-B. Fan and J.-G. Wang, J. Fuel Chem. Technol., 2011, 39, 918-923.

$11 \mathrm{~J} . \mathrm{Wu}, \mathrm{H}$. Zhu, Z. Wu, Z. Qin, L. Yan, B. Du, W. Fan and J. Wang, Green Chem., 2015, 17, 2353-2357.

12 F. Wang, G. Zhu, Z. Li, F. Zhao, C. Xia and J. Chen, J. Mol. Catal. A: Chem., 2015, 408, 228-236.

13 Q. Wu, M. Wang, Y. Hao, H. Li, Y. Zhao and Q. Jiao, Ind. Eng. Chem. Res., 2014, 53, 16254-16260.

14 Y. Wu, Z. Li and C. Xia, Ind. Eng. Chem. Res., 2016, 55, 18591865.

15 X. Fang, J. Chen, L. Ye, H. Lin and Y. Yuan, Sci. China: Chem., 2014, 58, 131-138.

16 J. Zhang, D. Fang and D. Liu, Ind. Eng. Chem. Res., 2014, 53, 13589-13597.

17 R. Wang, Z. Wu, Z. Qin, C. Chen, H. Zhu, J. Wu, G. Chen, W. Fan and J. Wang, Chemcatchem, 2014, 6, 3080-3083.

18 H. Li, H. Song, L. Chen and C. Xia, Appl. Catal., B, 2015, 165, 466-476.

19 E. Casas, B. Paredes, R. Van Grieken and J. M. Escola, Catal. Sci. Technol., 2013, 3, 2565-2570.

20 E. Casas, R. van Grieken and J. M. Escola, Appl. Catal., A, 2012, 437-438, 44-52.

21 S.-Y. Chen, T. Yokoi, C.-Y. Tang, L.-Y. Jang, T. Tatsumi, J. C. C. Chan and S. Cheng, Green Chem., 2011, 13, 2920.

22 J. Dhainaut, J.-P. Dacquin, A. F. Lee and K. Wilson, Green Chem., 2010, 12, 296-303.

23 J. C. Manayil, C. V. M. Inocencio, A. F. Lee and K. Wilson, Green Chem., 2016, 18, 1387-1394.

24 W. W. M. A. E. Somsook, J. Oleo Sci., 2013, 62, 435-442.

25 I. Mbaraka, J. Catal., 2003, 219, 329-336.

26 I. Mbaraka and B. Shanks, J. Catal., 2005, 229, 365-373.

27 I. Kim, J. Kim and D. Lee, Appl. Catal., B, 2014, 148-149, 295303.

28 D. Macina, Z. Piwowarska, K. Tarach, K. Góra-Marek, J. Ryczkowski and L. Chmielarz, Mater. Res. Bull., 2016, 74, 425-435.

29 Z. Xue, H. Shang, Z. Zhang, C. Xiong, C. Lu and G. An, Energy Fuels, 2017, 31, 279-286. 
30 J. F. D. Zhao, Q. Huo, G. H. F. N. Melosh, B. F. Chmelka and G. D. Stucky, Science, 1998, 279, 548-552.

31 S. Shylesh, S. Sharma, S. P. Mirajkar and A. P. Singh, J. Mol. Catal. A: Chem., 2004, 212, 219-228.

32 M. Breugst, R. Gree and K. N. Houk, J. Org. Chem., 2013, 78, 9892-9897.

33 J. S. Choi, D. J. Kim, S. H. Chang and W. S. Ahn, Appl. Catal., A, 2003, 254, 225-237.

34 J.-H. Won, H.-J. Lee, K.-S. Yoon, Y. T. Hong and S.-Y. Lee, Int. J. Hydrogen Energy, 2012, 37, 9202-9211.
35 M. Guan, W. Liu, Y. Shao, H. Huang and H. Zhang, Microporous Mesoporous Mater., 2009, 123, 193-201.

36 H. Jin, M. B. Ansari and S.-E. Park, Catal. Today, 2015, 245, 116-121.

37 B. Rác, P. Hegyes, P. Forgo and Á. Molnár, Appl. Catal., A, 2006, 299, 193-201.

38 J. Burger, E. Ströfer and H. Hasse, Chem. Eng. Res. Des., 2013, 91, 2648-2662. 